\title{
COMPORTAMENTO DE BRACATINGA (Mimosa scabrella) E SESBÂNIA (Sesbania sesban) EM ÁREAS DEGRADADAS PELA DISPOSIÇÃO DE RESÍDUOS PROVENIENTES DO PROCESSAMENTO DA BAUXITA
}

\section{BEHAVIOR OF BRACATINGA (Mimosa scabrella) AND SESBANIA (Sesbania sesban) IN DEGRADED AREAS BY DISPOSAL RESIDUE FROM BAUXITE PROCESSING.}

\section{Ferreira, C. A. G. ${ }^{1}$, Tauk-Tornisielo, S. M. ${ }^{2}$ and Chaves, M. M. F. ${ }^{3}$}

${ }^{1}$ Departamento de Refinaria e Mineração da Alcoa Alumínio S/A

${ }^{2}$ Centro de Estudos Ambientais da Universidade Estadual Paulista (UNESP) - Campus Rio Claro/SP

${ }^{3}$ Universidade Estadual de Campinas - UNICAMP - FEAGRI - Campinas/SP.

\section{RESUMO}

O retorno de horizontes superficiais do solo para áreas degradadas por atividade de disposição de resíduos tem sido prática rotineira e largamente utilizada. Para algumas empresas, no entanto, essa operação tem representado cerca de 70 a $80 \%$ dos custos finais de recuperação de áreas mineradas. $O$ presente trabalho teve como objetivo avaliar a contribuição de duas espécies leguminosas na colonização inicial de um solo degradado pela disposição de resíduo de bauxita pós processamento, em Poços de Caldas-MG. O plantio foi efetuado em Janeiro de 1999, utilizando-se leguminosas Mimosa scabrella e Sesbania sesban. Adotou-se o espaçamento de 2,0 x 1,5m, e o delineamento estatístico foi o de blocos casualizados no esquema fatorial $(3 \times 4 \times 2)$, sendo três doses de gesso diferentes, quatro espessuras de camada de solo superficial colocada sobre o resíduo e duas espécies vegetais. Foram feitas 4 repetições, com 5 plantas cada. Realizaram-se medições da altura total e o cálculo da taxa de mortalidade. Os resultados mostraram que o resíduo apresenta propriedades semelhantes a um solo salino-sódico, com altos valores para o pH e condutividade elétrica. Registrou-se ainda 
que as doses de gesso, as espessuras das camadas e as espécies influenciaram significativamente nos valores médios obtidos para as variáveis. Verificou-se a relação inversamente proporcional entre a taxa de mortalidade e os fatores dose de gesso e espessura da camada de solo colocado. Observou-se que doses crescentes de gesso e a espessura da camada de solo acarretaram decréscimo da taxa de mortalidade para as espécies. Para todas as variáveis estudadas, a sesbânia apresentou melhores resultados do que a bracatinga.

Palavras-chaves: áreas degradadas, bracatinga, sesbânia, gesso, recuperação.

\section{ABSTRACT}

Topsoil return in mining activities is a common and extensively used procedure. But, for some companies this operation may represent around $70-80 \%$ of all costs to reclaim degraded areas. This study evaluated the contribution of two leguminous species to improve the initial colonization of a damaged land by bauxite residue disposal after processing in Poços de Caldas-MG. Plants of Mimosa scabrella ("bracatinga") e Sesbania sesban ("sesban") were planted in January of 1999. Plants were spaced in 2 x $1,5 \mathrm{~m}$ and each plot received 25 plants. The statistical alignment was of randomized blocks in the factorial proportion $(3 \times 4 \times 2)$, with three of the gypsum dosage, four for the thickness layer of superficial soil laid over the residue and two species. Four repetitions were done, with five plants each. Measurements of total height were made and mortality rates were calculated. The results showed that the residue presented similar properties to a sodium-salt soil, with high $\mathrm{pH}$ value and electric conductivity. It was also observed that the gypsum doses, the layer thickness, and the species has significant influences in the average values registered for the variables studied. An inversely proportional relation was observed between the mortality rate and the variable gypsum dosage and layer thickness of the utilized soil, in which the increase of gypsum dosage and layer width corresponded to decreased mortality rate for the species. For all the variables studied, "sesban" showed better performance than "bracatinga".

Keywords: degraded area, bracatinga, sesban, rehabilitation, gypsum.

\section{INTRODUÇÃO}

\section{Aspectos gerais}

A derrubada indiscriminada das florestas e o uso inadequado dos recursos naturais têm provocado, dentre outros efeitos, degradação dos solos, redução da 
biodiversidade e alterações nas redes hidrográficas com perdas qualitativa e quantitativa das águas dos rios, lagos e reservatórios. Dentre as atividades antrópicas que vêm causando forte impacto ambiental negativo, pode-se citar a construção de estradas, urbanização, expansão agropecuária mal orientada, o uso e manejo inadequados do solo, atividades de mineração, construção de grandes lagos ou reservatórios artificiais, e áreas de disposição de resíduos sólidos industriais ou urbanos.

A refinaria da Alcoa Alumínio S/A, em Poços de Caldas/MG, gera 275.000 toneladas por ano de resíduo de bauxita, o qual é disposto em depósitos previamente preparados, que ocupam grandes áreas. O resíduo apresenta-se inerte e com sérias restrições químicas, físicas e biológicas. Várias alternativas de reutilização e reciclagem do resíduo foram estudadas, porém sem êxito significativo, sendo a reabilitação destas áreas talvez outra alternativa mais viável ambientalmente. A reabilitação da área degradada pela disposição do resíduo proveniente do processamento da bauxita apresenta limitações comprometedoras ao crescimento e desenvolvimento das plantas (MARSCHER, 1990; WONG e HO, 1991). Assim, a empresa vem concentrando esforços para reabilitação destas áreas e reintegração à paisagem natural.

É destaque atual a questão da recuperação de áreas degradadas, pois ambientes alterados têm sido gerados continuamente, e com várias feições e a consciência ambiental pressiona para suas recuperações. Esta preocupação quanto ao atual estado de comprometimento dos ecossistemas naturais e de áreas produtivas é pertinente, pois tem sido observado que a simples conservação dos recursos remanescentes não garante uma reversão do processo de degradação ambiental, seja em nível local, regional ou até planetário.

O sucesso dos projetos de florestamento e reflorestamento depende, entre outros fatos, da escolha correta das espécies vegetais. A escolha das espécies a serem usadas baseia-se em diferentes fatores ambientais do local a ser reflorestado, como também da história do ambiente do mesmo. A escolha será tanto mais correta, quanto maior for o conhecimento pertinente as espécies e este refere-se basicamente à autoecologia e ao comportamento silvicultural.

Os estudos sobre as espécies florestais nativas, foram anteriormente incipientes e relacionavam-se, principalmente, às características botânicas e dendrológicas. Pouco se conhecia sobre as características silviculturais, o padrão de crescimento e as exigências nutricionais das espécies no Brasil (GARRIDO, 1981). Atualmente, inúmeros estudos vêm sendo realizados sobre fitossociologia, fitogeografia e de modelos teóricos e experimentais de reflorestamento.

O plantio de espécies arbóreas sob diversas condições edafo-climáticas e o monitoramento de seu desempenho por meio de medições periódicas são, portanto, importantes no sentido de balizar a escolha e a melhor forma de plantá-las, 
principalmente em áreas degradadas (REICHMANN NETO, 1993).

O resíduo de bauxita juntamente com sulfato de cálcio (gesso) vem sendo estudado em solo, quanto aos mais diferentes aspectos. A alta sodicidade do resíduo pode promover aumento da concentração de sódio e da condutividade elétrica, quando aplicados em grandes quantidades, elevando esses níveis para valores deletérios às plantas. Além do efeito dos sais solúveis na disponibilidade da água para as plantas, têm efeitos que podem restringir igualmente o desenvolvimento das espécies vegetais (BARROW, 1982). Em qualquer circunstância, é fundamental o monitoramento do nível de sais, pois alta concentrações desses na solução do solo eleva a pressão osmótica, baixando consequentemente o potencial de água, além de causar desequilíbrio na relação sódio/cálcio, afetando a nutrição vegetal (MARSCHER, 1990). Vem sendo constatado que o uso do gesso pode reduzir os danos causados pela alta concentração do sódio do resíduo da bauxita. A presença do gesso altera a relação cálcio/sódio e favorece o deslocamento deste último pelo primeiro e a formação de sulfato de sódio de alta mobilidade no perfil do solo (WARD e SUMMERS, 1993)

\section{Caracterização das espécies florestais utilizadas}

$\mathrm{Na}$ escolha das espécies destinadas a um plantio, principalmente em áreas degradadas, é mais importante o conhecimento do habitat e o grupo ecológico a que pertence cada espécie, do que propriamente sua origem (exótica ou nativa). Optou-se por descrever resumidamente duas espécies de leguminosas colonizadoras que foram testadas oportunamente em outros programas de recuperação de áreas degradadas (REICHMANN et al, 1982).

\section{Mimosa scabrella Bentham - Mimosaceae (Bracatinga)}

Possui os seguintes nomes vulgares: bracatinga, bracaatinga, abracaatinga, bracatinho, paracaatinga. Ocorre de São Paulo ao Rio Grande do Sul em regiões de altitudes na floresta de pinhais. A madeira pode ser utilizada para lenha, carvão e construção civil. A árvore é bastante ornamental e pode ser usada em paisagismo, é semidecídua, heliófita, pioneira, apresentando certa indiferença às condições físicas do solo. É característica e exclusiva das matas de pinhais, principalmente de associações secundárias, onde pode formar povoamentos puros (LORENZI, 1992). Como planta pioneira de rápido crescimento pode estar presente nos plantios de áreas degradadas de preservação permanente em composições mistas. A bracatinga é uma espécie florestal, podendo ocorrer espontaneamente em terrenos rasos ou profundos e de fertilidade variável, na maioria solos pobres, com $\mathrm{pH}$ variando de 3,5 a 5,5, com textura franca argilosa e bem drenados. Em plantios, responde favoravelmente à profundidade efetiva e 
à riqueza química dos solos, particularmente à adição de fósforo (CARPANEZZI e CARPANEZZI, 1992).

Mimosa scabrella perde grandes quantidades de folhas ricas em nitrogênio, que se decompõem facilmente formando húmus e contribuindo, assim, para o aumento da matéria orgânica, para a fertilidade do solo e para melhoria das condições físicoquímicas, segundo o Centro Agronômico Tropical de Investigacion y Enseñanza (1991).

\section{Sesbania sesban (L.) Merril - Fabaceae (Sesbânia)}

Ocorre naturalmente no semi-árido até regiões subúmidas, com precipitação entre 500 e $2000 \mathrm{~mm}$. Adapta-se bem em locais com distribuição bimodal de precipitação (estações definidas seca e chuvosa) e tolera o encharcamento. Até $2000 \mathrm{~m}$ de altitude, a planta apresenta crescimento e desenvolvimento, sendo isso incerto em altitudes mais elevadas, não sendo tolerante ao frio, possuindo uma faixa de tolerância pequena em relação à alcalinidade e salinidade e apresenta curta longevidade. É uma espécie que cresce rapidamente até $8,0 \mathrm{~m}$ de altura com muitas ramificações, de madeira leve, sendo utilizada para forragem e adubação verde.

O presente trabalho teve como objetivo avaliar a capacidade de estabelecimento de plantas de Mimosa scabrella e Sesbania sesban em promover a colonização inicial de áreas degradadas pela disposição de resíduo proveniente do processamento da bauxita.

\section{MATERIAL E MÉTODOS}

\section{Aspectos gerais da área de estudo}

A área escolhida para desenvolvimento do trabalho localiza-se na Fábrica da Alcoa Alumínio S/A, em Poços de Caldas/MG, no local denominado Depósito de Resíduo de Bauxita I. A área foi utilizada para disposição do resíduo de bauxita desde 1970, tendo sido desativada em 1980, quando se esgotou sua capacidade de estocagem.

O município de Poços de Caldas com uma área de $533 \mathrm{Km}^{2}$, situa-se na região Sul do estado de Minas Gerais, cujo marco zero está entre as coordenadas $21^{\circ}$ 47'13' latitude Sul e 46³4'10"' longitude Oeste (MINAS GERAIS, 1926). O município 
localiza-se a $1.186 \mathrm{~m}$ de altitude em um planalto de forma elíptica, denominado planalto de Poços de Caldas (BALDASSARI, 1989).

O clima da região é do tipo $\mathrm{Cfb}$ (subtropical úmido), pela classificação de Köppen, e caracteriza-se por apresentar duas estações sazonais bem definidas, uma chuvosa, de outubro a março, e uma seca, de abril a setembro (INDI, 1977 citado por PEREIRA, 1986). A duração do período seco é de dois meses (julho e agosto), o índice pluviométrico anual é de 1.600 a $1.700 \mathrm{~mm}$, a temperatura média anual é de $24,3^{\circ} \mathrm{C}$, sendo a média das máximas de $25,9^{\circ} \mathrm{C}$ e das mínimas, de $7,4^{\circ} \mathrm{C}$. A ocorrência de geadas se verifica pelo menos uma vez por ano.

A vegetação original dos locais estudados era constituída pela dominância de contatos transicionais de floresta estacional semidecídua e floresta ombrófila mista. Estas matas caracterizam-se pela perda de grande parte das folhas no período frio e seco (semicaducifólia) entre junho e agosto (GATTO, 1983).

Os solos do planalto de Poços de Caldas caracterizam-se como associações de latossolos vermelho amarelo e vermelho escuro distróficos, podzólicos vermelho amarelo e cambissolos álicos e distróficos. Os perfis, à exceção dos latossolos, apresentam-se pouco desenvolvidos, com fase pedregosa e muito pedregosa de origem coluvial, com horizonte A moderado, textura média a muito argilosa e relevo ondulado a montanhoso. Nos Latossolos, ocorre também fase pedregosa e muito pedregosa (OLIVEIRA et al., 1987 citado por GISLER, 1995).

A área de estudo apresenta-se com declividade média de 10\%, localizando-se no antigo vale do Ribeirão Papão, sendo que, na década de 70 , foi barrado para construção do respectivo depósito, removendo-se a vegetação (campos de altitude e vegetação ciliar), em decorrência de terraplanagem. Não foi dado nenhum tratamento de adensamento ou compactação em função da baixa permeabilidade da argila $\left(10^{-6}\right)$. Nesta área, foram depositadas 633.000 toneladas de resíduo de bauxita da Alcoa. Ao término da capacidade de estocagem de resíduo, o local ficou abandonado até o final de 1997, quando se iniciaram os testes visando reabilitação. Quando da implantação do experimento, isto é, mais de 18 anos após o esgotamento da capacidade de estocagem do depósito, esta se encontrava com uma rala vegetação nas bordas, constituída predominantemente por gramíneas (Melinis minutiflora Beauv.) e uma leguminosa (Mimosa pseudincana discolor). Não se verificou na região central do depósito o estabelecimento de nenhum propágulo nativo ou exótico (observação própria dos autores). 
O preparo do solo foi realizado nos meses de novembro e dezembro de 1998 e constou das seguintes etapas: colocação do solo diretamente sobre o resíduo de bauxita; distribuição do material segundo as espessuras especificadas; coveamento manual nos sulcos, a cada 2,0m, em linha; e, sulcamento manual (enxada) das entrelinhas para semeadura das sementes das espécies estudadas.

\section{Produção das mudas}

As mudas utilizadas no plantio foram produzidas no Viveiro Florestal da Alcoa Alumínio, durante o ano de 1998. As sementes utilizadas foram colhidas em árvores localizadas na Região do Planalto de Poços de Caldas/MG e beneficiadas no Centro de Estudos e Pesquisas Ambientais da Alcoa. Todas as mudas foram produzidas em sacos de polietileno preto, utilizando-se o seguinte substrato: 6 partes de terra de subsolo; 2 partes de esterco de curral; 1 parte de casca de arroz carbonizada e 2,0kg de superfosfato simples $/ \mathrm{m}^{3}$. As mudas foram transportadas para o local do plantio em caminhão lonado. Por ocasião do plantio, as mudas apresentavam altura média de $35 \mathrm{~cm}$ e diâmetro do colo de 3,0mm. O espaçamento utilizado foi de $2,0 \times 1,5 \mathrm{~m}$, com distribuição ortogonal (2,0m entre as covas e $1,5 \mathrm{~m}$ entre os sulcos), visando rápido recobrimento da área. Entre os sulcos procedeu-se à semeadura das sementes de mutambo, aroeira, bracatinga, trema, eucalipto, alfeneiro e sesbânia.

\section{Adubação e plantio}

Diante da falta de informações sobre as exigências nutricionais das espécies testadas, a adubação utilizada seguiu a recomendação geral para plantio de mudas de espécies florestais, em áreas degradadas pela mineração de bauxita, no Planalto de Poços de Caldas/MG, constituindo-se de $150 \mathrm{~g}$ de adubo NPK/cova.

Para verificar a influência da adição do gesso sobre o desenvolvimento das plantas, fez-se uma adubação com três doses distintas, correspondentes a 10,20 e 30 toneladas/ha e quatro níveis de espessuras de camadas de solo de horizonte A colocadas sobre a superfície do resíduo. O plantio foi realizado entre os dias 02 e 08 de janeiro de 1999.

\section{Delineamento estatístico}

O delineamento estatístico adotado foi o de blocos casualizados, no esquema fatorial $(3 \times 4 \times 2)$. O total de tratamentos foi igual a 84 (três doses $\times$ quatro espessuras de 
camada de solo $\mathrm{x}$ duas espécies florestais). Foram realizadas quatro repetições por tratamento, com parcelas compostas de 20 plantas da mesma espécie, sem linha de bordadura. A área útil de cada sub-parcela foi de $120 \mathrm{~m}^{2}$, totalizando uma área útil de $5860 \mathrm{~m}^{2}$. Os tratamentos foram: doses de gesso $(10,20$ e 30 toneladas/ha); espessura da camada $(10,20,30$ e $40 \mathrm{~cm})$; e, espécies (bracatinga e sesbânia).

Os dados foram arquivados no programa Excel e analisados com uso do programa estatístico JMP/SAS Institute Inc., segundo o modelo de análise de variância descrito por Little e Hills (1978). As médias foram comparadas pelo teste de Tukey, em nível de $5 \%$ de significância. As análises de regressão foram feitas usando o mesmo programa.

\section{Avaliação da altura total e mortalidade das plantas estudadas}

O acompanhamento do desenvolvimento das espécies vegetais no campo foi realizado por meio de medições periódicas das variáveis altura da planta. As avaliações foram realizadas aos 6, 12 e 18 meses após o plantio. Foram realizadas no total de três medições, nas seguintes datas e idades, respectivamente: 03/99 (6 meses); 09/99 (12 meses); 03/2000 (18 meses). As características avaliadas foram as seguintes:

\section{a) Altura total da planta}

A medição desta variável foi tomada entre a base do caule e a gema apical principal. No caso de espécies sem uma gema apical principal definida, a altura foi considerada até um plano horizontal imaginário, passando pela gema situada no ponto mais alto. Para a obtenção dessas medidas, utilizou-se um cano de PVC de 4,0m de comprimento, graduado de $10 \mathrm{em} 10 \mathrm{~cm}$.

\section{b) Mortalidade}

Determinada em porcentagem, com base no número de indivíduos remanescentes em comparação ao número de indivíduos plantados, em cada avaliação e, para cada espécie. Consideraram-se mortos os indivíduos aparentemente secos, sem folhas e caules e ramos quebradiços ou que se quebravam facilmente na base após flexionamento do caule. 


\section{RESULTADOS E DISCUSSÃO}

Sendo a precipitação um fator que influencia diretamente o estabelecimento, crescimento e desenvolvimento das plantas, esta foi registrada aos 6,12 e 18 meses após as semeaduras das espécies vegetais, recebendo 1351,25; 153,25 e 1252,25mm de água, respectivamente.

\section{Altura total da planta}

Os valores das alturas das plantas em relação as diferentes quantidades de gesso utilizadas estão na Figura 1. Analisando-se estatisticamente os valores da altura total da planta, verificou-se que estes foram diferentes significativamente em relação aos fatores utilizados, com interação dupla e tripla entre os fatores $(\alpha=5 \%)$. Assim observou-se que doses de gesso $\mathrm{x}$ espessuras das camadas de solo $\mathrm{x}$ espécies vegetais usadas influenciaram nos valores médios registrados para a variável altura. As interações significativas entre doses de gesso x espessura da camada, doses de gesso x espécie e espessura da camada $\mathrm{x}$ espécie indicam que a variável altura é dependente da espessura da camada de solo, doses de gesso e espécies, portanto, estas variáveis não apresentam comportamento uniforme. A interação tripla estatisticamente significativa indica a dependência dos três fatores estudados (Tabela 1). 


\section{Bracatinga (Mimosa scabrella)}

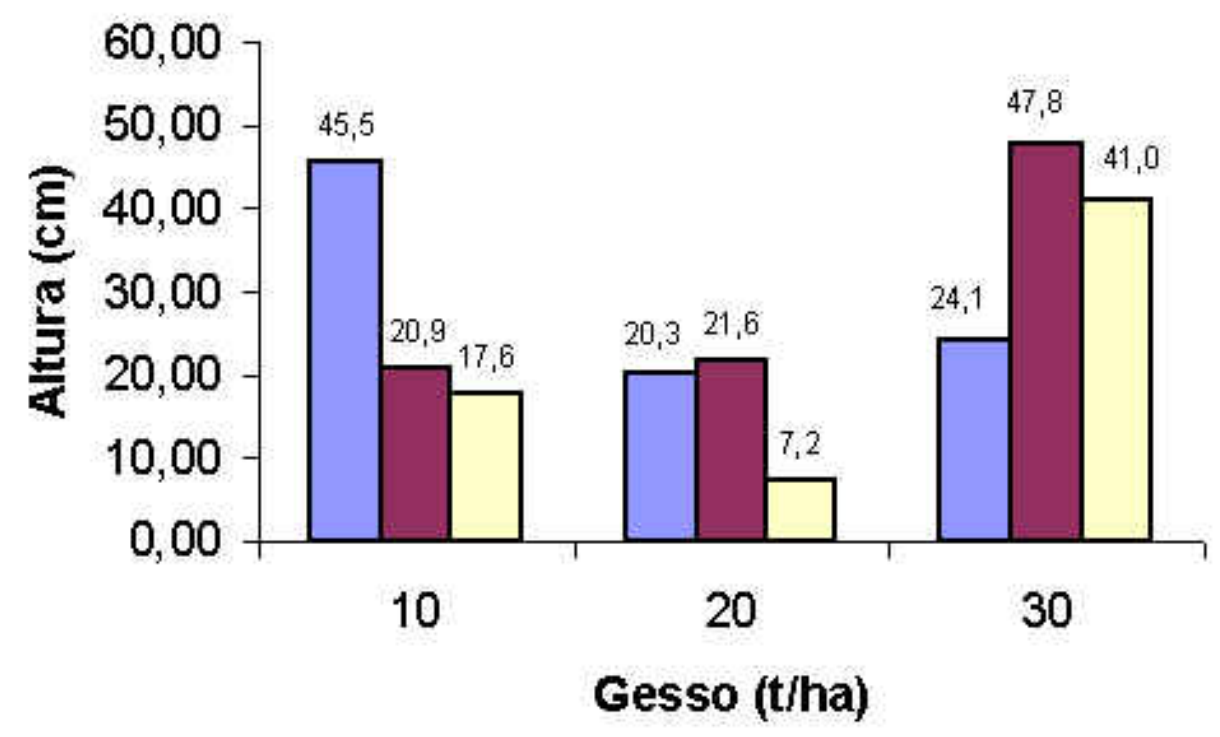

\section{Sesbânia (Sesbania sesban)}

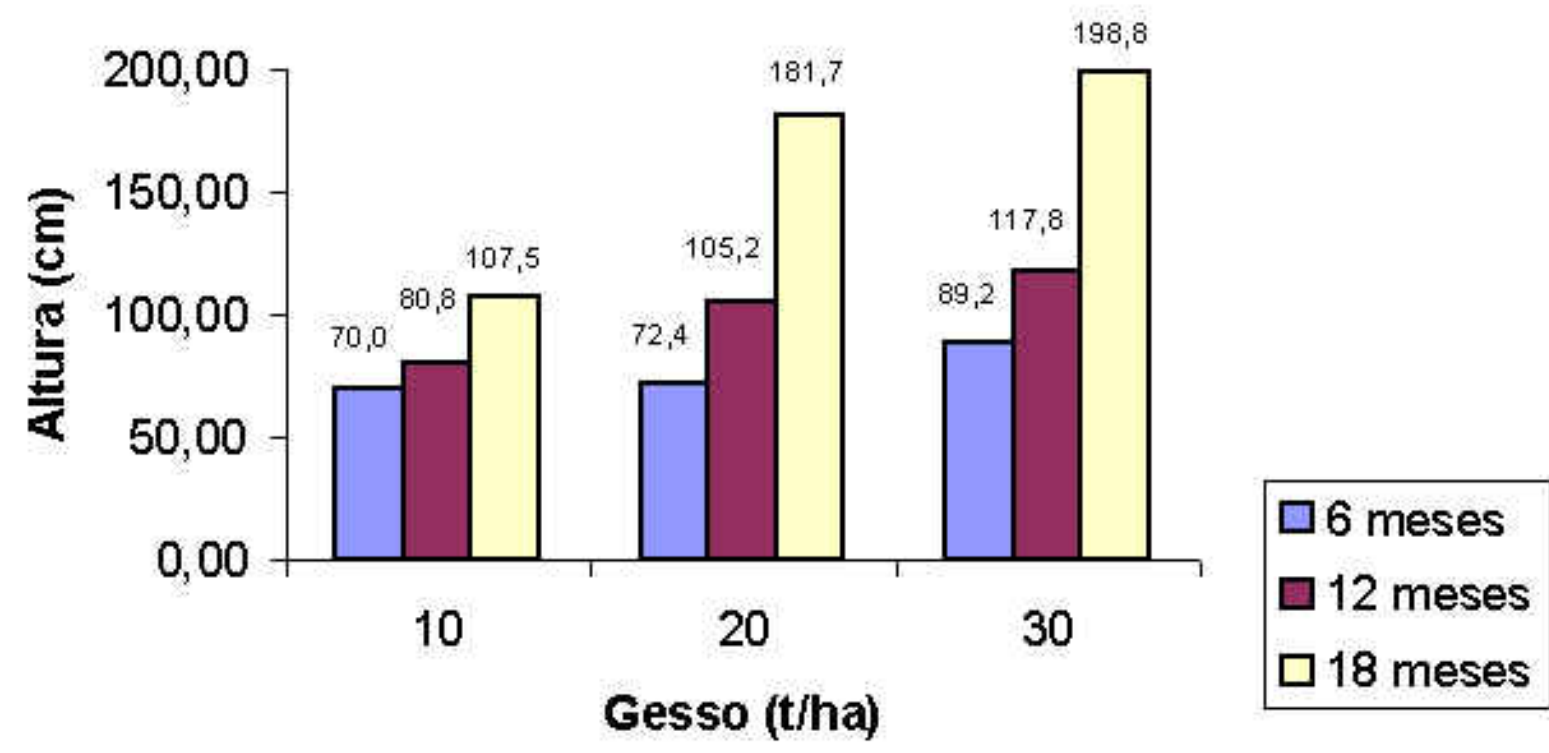

Figura 1. Valores médios para a variável altura total $(\mathrm{cm})$ das espécies em relação a quantidades de doses de gesso utilizadas.

Tabela 1. Análise estatística realizada para a variável altura e diâmetro do colo para os fatores doses de gesso $(\mathrm{G})$, espessura da camada de solo (C) e tipos de espécies vegetais (E). 


\begin{tabular}{|c|c|c|c|}
\hline & \multicolumn{3}{|c|}{ Avaliação (meses) } \\
\hline Fator & 6 & 12 & 18 \\
\hline $\mathrm{G}$ & $* *$ & $* *$ & $* *$ \\
\hline $\mathrm{C}$ & $* *$ & $* *$ & $* *$ \\
\hline $\mathrm{E}$ & $* *$ & $* *$ & $* *$ \\
\hline$G \times E$ & $* *$ & $* *$ & $* *$ \\
\hline $\mathrm{G} \times \mathrm{C}$ & $* *$ & $* *$ & $* *$ \\
\hline $\mathrm{C} \times \mathrm{E}$ & $* *$ & $* *$ & $* *$ \\
\hline $\mathrm{G} \times \mathrm{C} \times \mathrm{E}$ & $* *$ & $* *$ & $* *$ \\
\hline $\mathrm{CV}$ & 38,49 & 50,16 & 56,39 \\
\hline
\end{tabular}

\section{Interação entre espécies e doses de gesso}

Verificou-se que houve diferenças estatísticas significativas $(\alpha=5 \%)$ para a interação entre espécies e doses de gesso, relacionada à altura total da planta. Independente das doses de gesso, verificou-se que sesbânia apresentou maiores valores médios do que bracatinga para a altura total, com aumentos crescentes. Os menores valores ocorreram nas parcelas onde as quantidades de doses de gesso também foram menores. A espécie bracatinga aos seis meses de crescimento apresentou pouco crescimento nas parcelas contendo maiores quantidades de gesso. Este resultado deve estar relacionado com a alta concentração de sais decorrentes das doses de gesso usadas em menores espessura da camada de solo, juntamente com a distribuição da chuva, acarretando saturação do meio (GUIMARÃES, 1986).

Comparando-se o crescimento de bracatinga em relação ao tamanho médio das mudas no plantio, nas parcelas com 10 e 20t/ha, observou-se que bracatinga apresentou o pior desempenho, sendo que a sesbânia manteve crescimento crescente ao longo das medições de crescimento das mudas. Ward (1982), entretanto, incorporando $5 \%$ de gesso ao solo, aumentou o crescimento acima de $100 \%$ em plantas cultivadas em resíduo de bauxita. Barrow (1982) obteve resposta efetiva do gesso no crescimento de plantas cultivadas em resíduo com incorporação de $5 \%$ de gesso e de uma lâmina de água. na ausência do gesso nenhuma espécie estudada se desenvolveu.

A utilização de sais solúveis de cálcio de alta solubilidade, de produtos 
ácidos ou formadores de ácidos foi recomendada para substratos com carbonatos de metais alcalinos terrosos, condição esta do resíduo do refino de bauxita (FASSBENDER, 1987). O uso de aditivos químicos para as condições do solo, no entanto, muitas vezes é limitado, principalmente pelo elevado custo e a pouca disponibilidade. O gesso assim fica restrito às áreas localizadas próximas às fontes produtoras

O gesso em solos ácidos pode ser usado como fonte de cálcio e enxofre, na forma de sulfato, para as plantas, e como corretivo para subsolos deficientes em cálcio por causa de lixiviação do sulfato de cálcio aplicado na superfície (VITTI e MALAVOLTA, 1985). A reação entre o gesso e o sódio trocável é uma reação de troca iônica e de equilíbrio. O sucesso na reabilitação de áreas ocupadas com resíduo alcalino do refino de bauxita tem sido apresentado como possível, desde que hajam tratamentos que possam reduzir a salinidade, alcalinidade e sodicidade.

\section{Interação entre espécies e espessura da camada de solo}

Os resultados mostraram que para sesbânia e bracatinga somente para o nível $4(40 \mathrm{~cm})$ do fator espessura da camada, houve correlação positiva entre a variável altura e o fator espessura da camada, sendo que a medida que aumentou-se a espessura da camada de solo de horizonte A colocada sobre o resíduo, aumentaram-se os valores médios observados para a variável altura (Figura 2).

A sesbânia apresentou incrementos crescentes ao longo de todas avaliações. As diferenças nas taxas de crescimento foram menos perceptíveis aos seis e doze meses, sendo mais marcantes aos 18 meses. Entre os níveis 3 e $4(30$ e $40 \mathrm{~cm})$ não foi observada diferença significativa, sendo economicamente mais viável usar o nível $3(30 \mathrm{~cm})$.

A bracatinga apresentou a mesma tendência no comportamento para os níveis 1,2 e 3 do fator espessura da camada, registrando-se ao longo das avaliações incrementos decrescentes, e, com valores médios menores comparativamente ao tamanho da muda ao plantio. Vale ressaltar a alta sensibilidade desta espécie para este fator, revelada claramente para o nível $4(40 \mathrm{~cm})$ onde registrou-se incrementos crescentes ao longo das avaliações. O maior valor médio observado foi $73,95 \mathrm{~cm}$ ao final de dezoito meses.

A utilização de solo superficial de floresta em áreas mineradas proporcionou uma comunidade capaz de promover cobertura rápida e efetiva, com o mesmo potencial desenvolvido nas florestas predominantes da área. Em determinados casos esta metodologia pode reduzir a necessidade de semeaduras e plantio de mudas, diminuindo os custos da recuperação (FARMER JUNIOR et al., 1982). A adição de solo da camada superficial é uma das técnicas fortemente recomendadas para reabilitação de solos degradados (GONÇALVES et al., 1991), sendo isto também confirmado através dos 
resultados aqui obtidos.
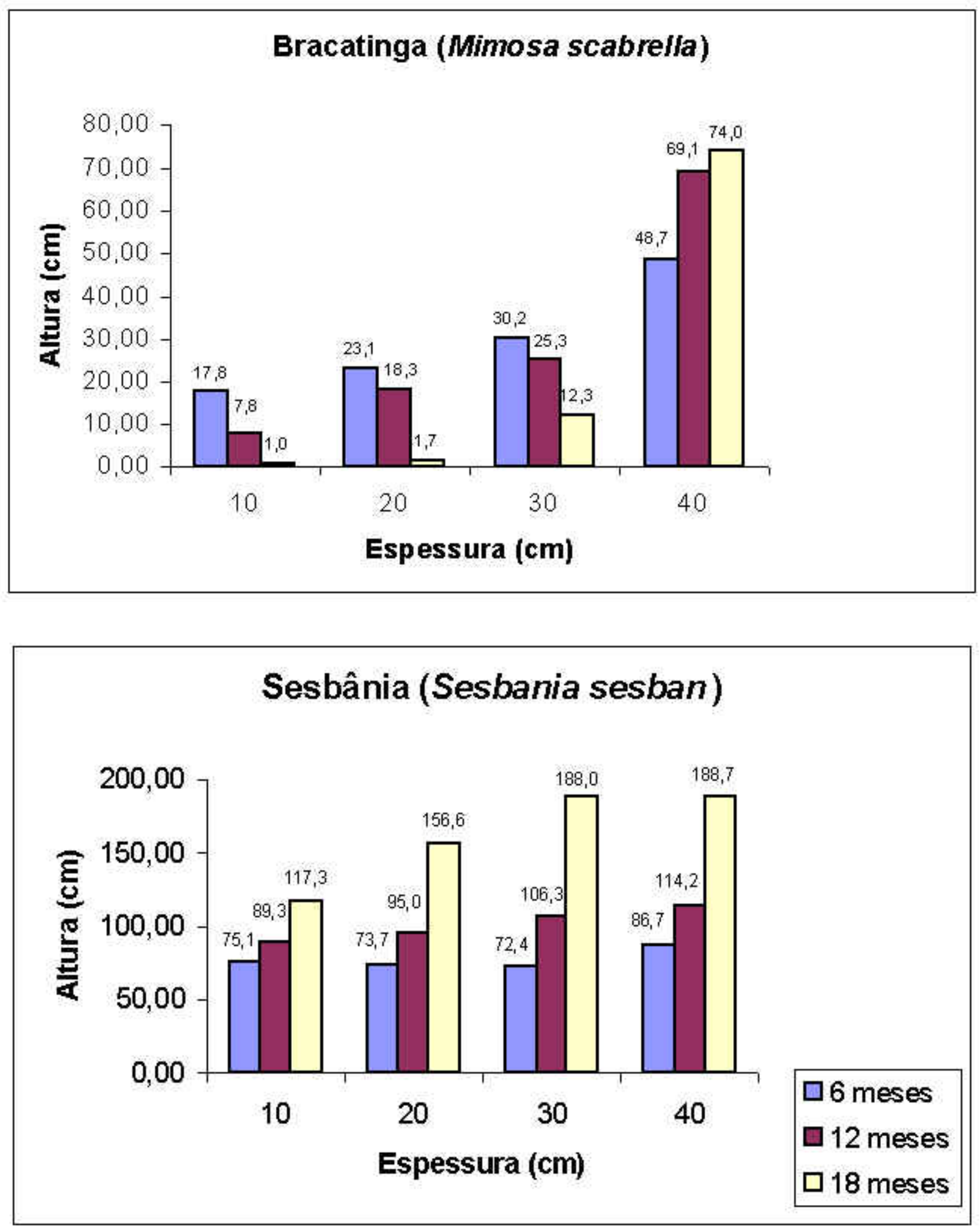

Figura 2. Valores médios para a variável altura total $(\mathrm{cm})$ das espécies utilizadas em relação às diferentes espessuras da camada de solo superficial colocada sobre o resíduo.

Foi estudado o efeito do plantio de bracatinga e gramíneas em áreas de afloramento do horizonte $\mathrm{C}$, área de empréstimo, observando-se alterações como a formação de um pequeno horizonte superficial orgânico, diminuição nos valores de 
densidade do solo e incorporação de matéria orgânica (REICHMANN et al., 1982). Os resultados aqui obtidos, entretanto, mostraram que a sesbânia foi mais eficiente no plantio do que a bracatinga, dentro das condições ambientais presentes na área de estudo e nos fatores estudados.

\section{Mortalidade das espécies estudadas}

As maiores taxas de mortalidade foram verificadas nas parcelas que receberam recobrimento de solo sobre o resíduo, com espessura de camada de $10 \mathrm{~cm}$, independentemente das doses de gesso aplicadas. Os dados mostraram relação inversamente proporcional entre mortalidade com os fatores espessura da camada de solo e doses de gesso, ou seja, à medida que se diminui a espessura da camada ou a dose de gesso aumentou a taxa de mortalidade das mudas (Figura 3).

Durante o período experimental as plantas passaram por dois períodos chuvosos com taxas de precipitação superiores a 1000mm (aos 6 meses e a partir dos 12 meses). As altas taxas de mortalidade registradas no período inicial para os menores níveis do fator espessura da camada, provavelmente deu-se em função da alta concentração de sais na superfície decorrentes das doses de gesso e taxas de precipitação (GUIMARÃES, 1986). Registraram-se taxas de precipitação acumulada de 1351,40mm; $153,25 \mathrm{~mm}$ e $1252,25 \mathrm{~mm}$ aos 6,12 e 18 meses respectivamente.

Analisando-se a performance das espécies com relação ao fator doses de gesso, verificou-se comportamento variável entre os tratamentos. Para aplicação de $10 \mathrm{t} / \mathrm{ha}$ de gesso e espessura da camada de $10 \mathrm{~cm}$, registraram-se as menores taxas de mortalidade para sesbânia. Bracatinga apresentou $100 \%$ de mortalidade para os tratamentos 1 e $2(10$ e $20 \mathrm{~cm})$ do fator espessura da camada de solo. Verificou-se o efeito significativo marcante revelado para sesbânia neste tratamento, com redução nas taxas de mortalidade de $35 \%$. Constatou-se que houve diminuições significativas na taxa de mortalidade para os tratamentos das camadas de 30 e $40 \mathrm{~cm}$ de espessura, confirmando o efeito deste fator na sobrevivência das espécies. Para sesbânia, observou-se um aumento na taxa de mortalidade para a camada de solo de $40 \mathrm{~cm}$ em relação à camada de $30 \mathrm{~cm}$, provavelmente em função de algum efeito local. Para bracatinga, o efeito dos níveis (3 e 4) deste fator foi marcante, registrando-se sobrevivência destes indivíduos somente nestes tratamentos.

No tratamento com 20t/ha, a sesbânia apresentou maior taxa de sobrevivência em todas as espessuras da camadas de solo utilizadas, sendo que a adição de gesso possibilitou uma redução da taxa de mortalidade de 40\% (Figura 3). Assim como foi observado para o nível 1 do fator dose de gesso (10t/ha), verificou-se mortalidade total para bracatinga dentro das espessuras de camada de 10 e $20 \mathrm{~cm}$.Para o 
fator espessura da camada de solo no nível $2(20 \mathrm{~cm})$, não se identificou taxa de mortalidade para sesbânia.

Como para os outros níveis do fator, verificou-se para 30t/ha que as maiores taxas de mortalidade foram verificadas nos tratamentos correspondentes às menores espessuras de camada de solo (Figura 3). Como observado para os níveis 1 e 2 do fator doses de gesso, a mortalidade foi de $100 \%$ para bracatinga dentro do nível $1(10 \mathrm{t} / \mathrm{ha})$ do fator espessura da camada de solo. Para as espécies utilizadas houve reduções significativas na taxa de mortalidade com o aumento da espessura da camada e doses de gesso. A sesbânia apresentou menores taxas de mortalidade, sendo que o efeito da dose foi marcante a partir da camada de solo de $20 \mathrm{~cm}$.

O incremento na produção de espécies vegetais foi maior para aquelas mais sensíveis a acidez do solo. $\mathrm{O}$ trevo semeado com alfafa, entretanto, não sobreviveu a essas condições do solo, mesmo quando procurou-se alcalinizar o meio (SUMMERS e BRADBY, 1993).

\section{CONCLUSÕES}

Os resultados permitiram concluir que Sesbania sesban apresentou maior capacidade de colonização inicial das áreas degradadas pela disposição de resíduo de bauxita, aqui estudadas, do que Mimosa scabrella.

Quanto maiores a espessura da camada de solo introduzida e também das doses de gesso utilizadas maiores foram os incrementos na altura total e no diâmetro do caule das espécies vegetais utilizadas.

Altas doses de gesso em parcelas que receberam pequenas espessuras da camada de solo acarretam saturação de sais no meio, inibindo o crescimento de bracatinga.

A quantidade de 30t/ha acarretou incrementos crescentes nas espécies vegetais utilizadas, ressaltando-se a sesbânia que apresentou melhor performance, sendo que nas parcelas submetidas ao tratamento nível $1(10 \mathrm{~cm})$, esta espécie foi a única que pode ser indicada para o plantio.

As maiores taxas de mortalidade foram verificadas para o nível de $10 \mathrm{~cm}$ do fator espessura da camada de solo, independentemente das doses de gesso aplicadas. Observou-se que à medida que se aumentou a espessura da camada de solo e a dose de gesso houve diminuição significativa na taxa de mortalidade. 


\section{AGRADECIMENTOS}

Os autores agradecem o fundamental apoio dos funcionários da Alcoa Alumíno S/A e aos Funcionários do CEA/UNESP Campus de Rio Claro/SP.

\section{Gesso (10t/ha)}

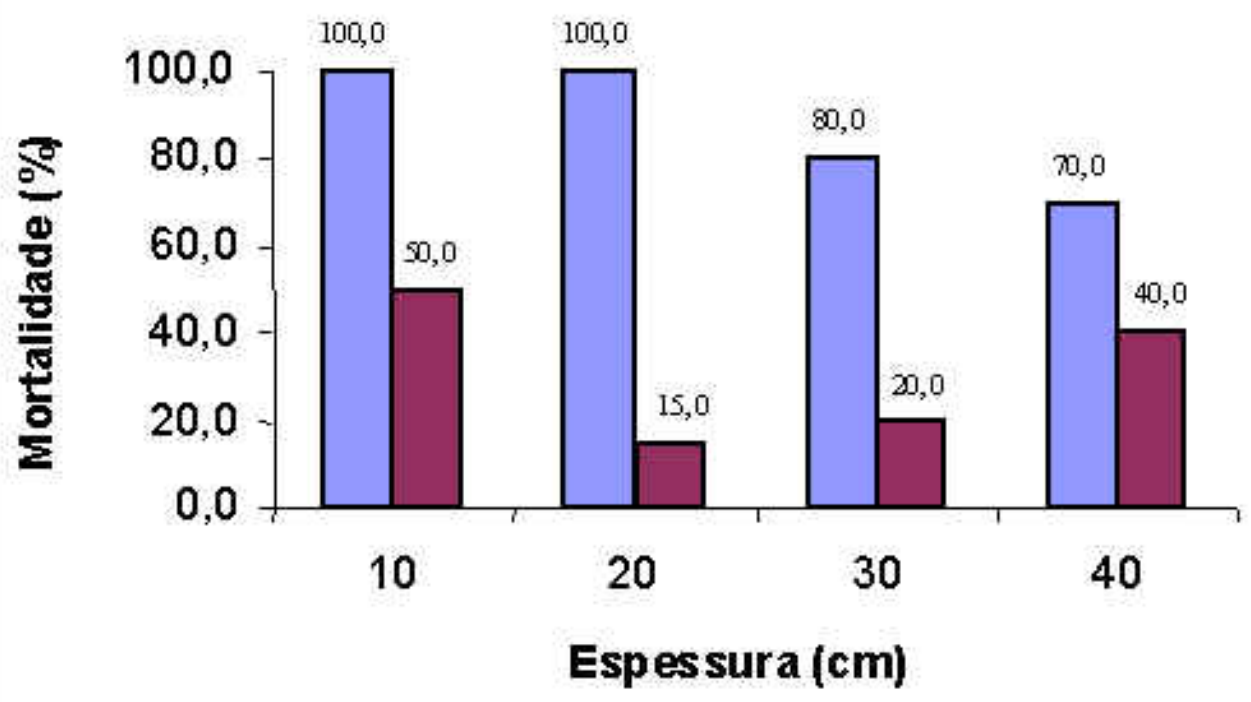



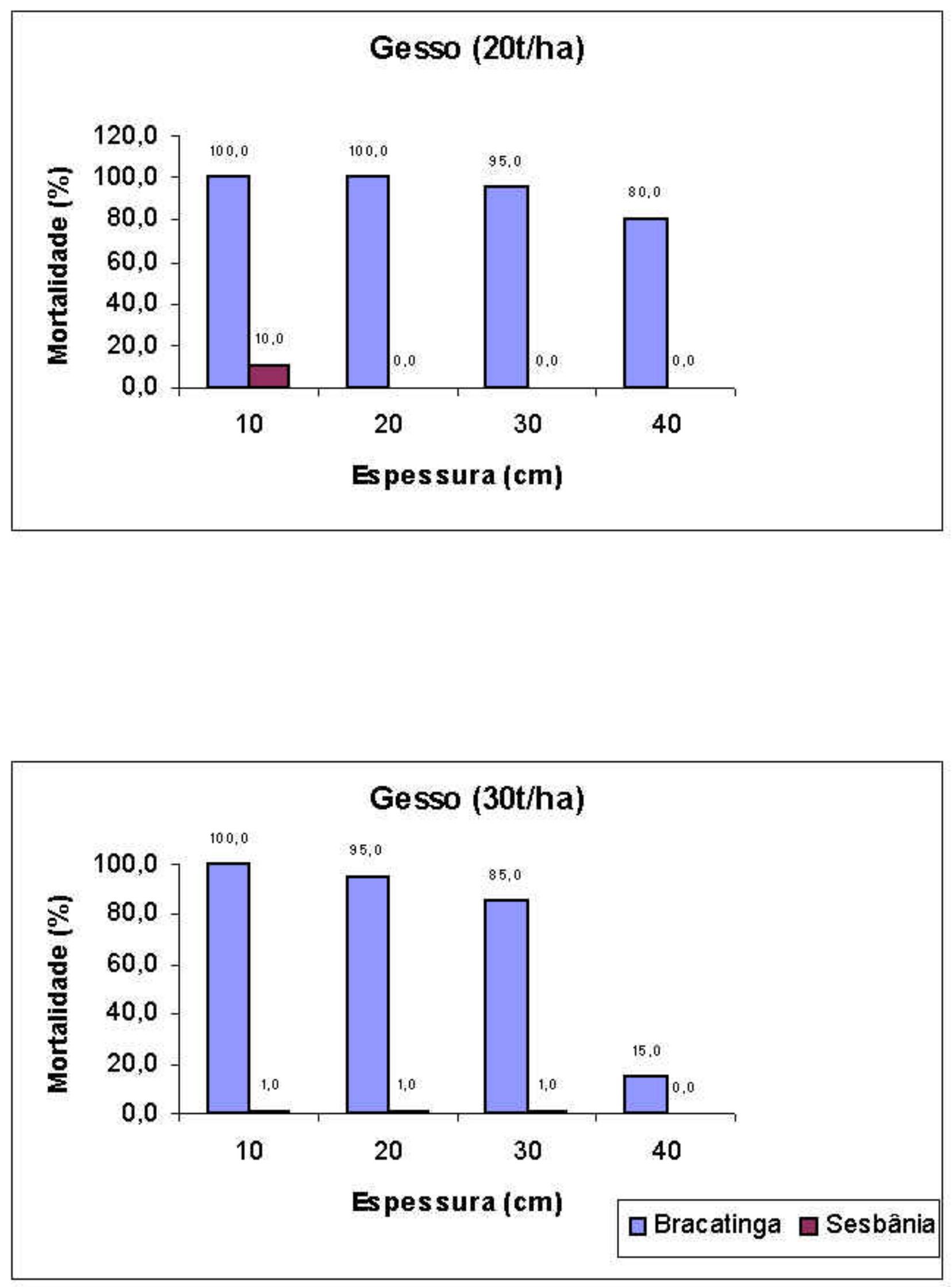

Figura 3. Valores médios para a variável mortalidade (\%) para a interação entre os fatores espessura da camada e doses de gesso (A, 10cm; B, 20cm; C, 30cm e D, $40 \mathrm{~cm})$. 


\section{REFERÊNCIAS}

BALSASSARI, I. B. Flora de Poços de Caldas, Familia: Melastomastaceae. Campinas, 1989. 265f. Dissertação (Mestrado em Biologia) - Insituto de Biologia Universidade Estadual de Campinas.

BARROW, N.J. Possibility of using caustic residue from bauxite for improving the chemical and physical properties of sandy soils. Australian Journal Agricultural Research, Australia, v.33, p.275-285, 1982.

CARPANEZZI, A.A; CARPANEZZI, O.T.B. O cultivo da bracatinga (Mimosa scabrella Bentham) no Brasil e prioridades para o aperfeiçoamento. In: CONGRESSO FLORESTAL ESTADUAL, 7, Nova Prata, 1992. Anais. Santa Maria: Universidade Federal do Rio Grande do Sul, 1992. V.2, p.640-655.

CENTRO AGRONOMICO TROPICAL DE INVESTIGACION Y ENSEÑANZA. Bracatinga (Mimosa scabrella Benth.) especie de arbol de uso multiple en america central. Projeto Cultivo de Arboles de Uso Múltiple (MADALENA). Turrialba: Costa Rica, 1991. 50p. (Série Técnica, 169).

FARMER JUNIOR, R.E., CUNNINGHAM, M., BARNHILL, M.A. First-year development of plant comunities originating from forests topsoils placed on sourhern Appalachion minesoils. Journal of Applied Ecology, Oxford, 19, p.283-94. 1982.

FASSBENDER, H.W. Química de suelos com énfasis en suelos de América Latina. 2.ed., San José, Costa Rica: IICA, 1987. 420p.

GARRIDO, M.A.O. Características silviculturais e conteúdo de nutrientes no folhedo de alguns povoamentos puros e mistos de espécies nativas. Piracicaba, 1981. 105f. Dissertação (Mestrado em Ciências Florestais) - Escola Superior de Agricultura "Luiz de Queiroz", Universidade de São Paulo.

GATTO, L.C.S. Geomorfologia. In: PROJETO RADAM BRASIL, Ministério das Minas e Energia. Levantamento de recursos naturais. Rio de janeiro, 1983. Folhas SF 23/24, v 32. P. 385-535.

GISLER, C.V.T. $O$ uso da serapilheira na recomposição vegetal em áreas mineradas de bauxita. Poços de Caldas, MG. São Paulo. 147f. Dissertação ( Mestrado em Ecologia), Universidade de São Paulo.

GONÇALVES, J.C., CERVENCA, C.J., TOLEDO, A.E.P. Recuperação de áreas degradadas. In: WORKSHOP SOBRE RECUPERAÇÃO DE ÁREAS DEGRADADAS, 1. 1990, Itaguaí. Anais... Itaguaí, RJ: UFRRJ, 1991. P.89-101. 
GUIMARÃES, P.C.G. O gesso agrícola na neutralização do alumínio nas camadas subsuperficiais do solo: Aplicações às culturas anuais e perenes: SEMINÁRIO SOBRE O USO DO FOSFOGESSO NA AGRICULTURA, 1, 1985. Brasília. Anais... Brasília: EMBRAPA-DDT, 1986. p. 145-165.

LITTLE, T.M., HILLS, F.J. Agricultural experimentation: design and analysis. New York: John Wiley, 1978. 350p.

LORENZI, H. Árvores brasileiras: manual de identificação e cultivo de plantas arbóreas nativas do Brasil. Nova Odessa: Ed. Plantarum, 1992. 352p.

MARSCHER, H. Mineral nutrition of higher plants. San Diego: Academic Press, 1990. $674 p$.

MINAS GERAIS. Secretaria de Agricultura. Atlas horográfico municipal: mapa do município de Poços de Caldas. Belo Horizonte, v.2, 1926.

PEREIRA, S. C. Contribuição ao conhecimento das gramíneas de Poços de Caldas, MG. Campinas, 1986. 516f. Tese (Doutorado em Biologia) - Instituto de Biologia Universidade Estadual de Campinas.

REICHMANN NETO, F. Recuperação de áreas degradadas na Região Sul. In: CONGRESSO FLORESTAL PANANMERICANO, 1 e CONGRESSO FLORESTAL BRASILEIRO, 7, Curitiba, Anais.... Curitiba, 1993, v.3, p.102-107.

REICHMANN NETO, F.,. SANTOS FILHO, A. Desenvolvimento de solos em áreas de empréstimo, resultante do plantio de gramíneas e bracatinga. In. CONGRESSO NACIONAL SOBRE ESSÊNCIAS NATIVAS. 1982. Campos do Jordão. Anais...Campos do Jordão: Silvicultura em São Paulo. V.16-a, Parte 3. São Paulo, 1982. P.1896-1899.

SUMMERS, R.N., BRADBY, K. Use of bauxite residue en the Peel-Harvey coastal plain catchment. Western Australian: Western Australian Department of Agriculture, 1993. $57 \mathrm{p}$.

VITTI, G.C., MALAVOLTA, E. Fosfogesso: uso agrícola. In: SEMINÁRIO SOBRE CORRETIVOS AGRÍCOLAS, 1985, Piracicaba. Resumos: Piracicaba: Fundação Cargil, 1985. P. 161-201.

WARD, S.C. The use of the fine residue from bauxite refining as a soil amendment. Murdoch, 1986. 318p. Thesis (PhD of Environmental and Life Science) - School of Environmental and Life Science - University, Western Australia.

WONG, J.W.C.; HO, G.E. Effects of gypsum and sewage sludge amendment on physical 
properties of fine bauxite refining residue. Soil Science, v.152, p.326-332, 1991. 